ISSN = 1980-993X-doi:10.4136/1980-993X
www.agro.unitau.br/ambi-agua
E-mail: ambi-agua@agro.unitau.br
Tel.: (12) 3625-4116

\title{
Avaliação do desempenho de equações de regionalização de vazões na bacia hidrográfica do Ribeirão Santa Bárbara, Goiás, Brasil (doi:10.4136/ambi-agua.53)
}

\author{
Ana Paula Fioreze'; Luiz Fernando Coutinho de Oliveira²; Alexandre Puglisi \\ Barbosa Franco ${ }^{3}$

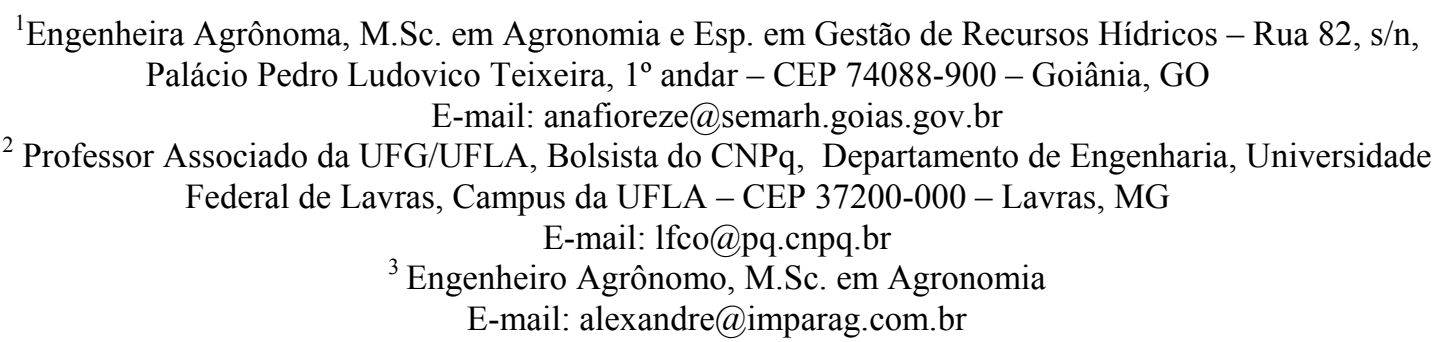

\section{RESUMO}

A disponibilidade de informações sobre as vazões de referência é essencial para a gestão dos recursos hídricos. Grande parte das pequenas bacias hidrográficas brasileiras não tem suas vazões monitoradas. A regionalização de vazões é uma das alternativas para a obtenção dessas informações. No entanto, esses modelos constituem uma representação simplificada dos fenômenos naturais, sujeita a erros, e devem ser testados antes de sua aplicação. Este trabalho avaliou o desempenho de equações de regionalização das vazões média de longo período, mínima, máxima, com $95 \%$ de permanência, mínima com sete dias de duração e dez anos de tempo de retorno e médias mensais ajustadas para a região da bacia hidrográfica do Ribeirão Santa Bárbara, em Goiás, compreendida entre as coordenadas $17^{\circ} 45^{\prime}$ e $18^{\circ} 15^{\prime}$ de

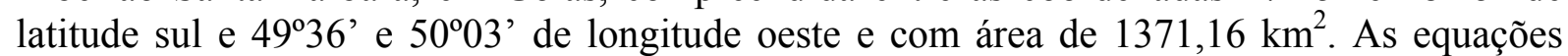
foram consideradas satisfatórias para estimar as vazões médias na saída dessa bacia hidrográfica, mas inadequadas para os eventos extremos (vazões máximas e mínimas), obtendo-se melhores resultados com as equações ajustadas após a definição de regiões homogêneas. A Q 95 , vazão de referência à outorga no Estado de Goiás, foi satisfatoriamente estimada pela equação que envolve a área e a densidade de drenagem da bacia, produzindo resultados mais significativos que os fornecidos por poucas medições efetuadas no local.

Palavras-chave: recursos hídricos; disponibilidade hídrica; vazões de referência.

\section{Evaluation of regionalization flows models performance at Santa Bárbara River Basin, Goiás, Brazil}

\begin{abstract}
Information on river flows is essential for water resources management. Most of the Brazilian small watersheds is ungauged. Regionalization of hydrologic information is an alternative way to get this lacking information. The regionalization models, however, are a simplified representation of natural phenomena, what could lead to miscalculation. Therefore, these models should be tested before being used as a management tool. This paper evaluates the performance of the regionalization models created for the Santa Bárbara River Basin
\end{abstract}


FIOREZE, A. P.; OliveIRA, L. F. C.; FRANCO, A. P. B. Avaliação do desempenho de equações de regionalização de vazões na bacia hidrográfica do Ribeirão Santa Bárbara, Goiás, Brasil. Ambi-Agua, Taubaté, v. 3, n. 2, p. 62-76, 2008. (doi:10.4136/ambi-agua.53)

region, in Goiás. This river basin is located between $17^{\circ} 45^{\prime}$ and $18^{\circ} 15^{\prime}$ South and $49^{\circ} 36^{\prime}$ and $50^{\circ} 03^{\prime}$ ' West and has a catchment area of $1371,16 \mathrm{~km}^{2}$. The models estimate average streamflow, maximum streamflow, minimum streamflow, the $95 \%$ duration streamflow, the seven day, ten years, minimum streamflow and the monthly-average streamflows. The tested streamflow regionalization models proved to be good enough for average flows, but not for maximum and minimum events. The models based on homogeneous regions were superior to those that ignored that aspect. The model that uses drainage area and density to estimate the $95 \%$ duration streamflow could be used in water resources management with little error. The use of this model would better represent the water availability at Santa Bárbara River Basin than a few local measurements currently used.

Keywords: water resources; water availability; reference flows.

\section{INTRODUÇÃO}

Para a adequada gestão dos recursos hídricos, é preciso conhecer o comportamento hidrológico das bacias hidrográficas. Segundo Arnéz (2002), é necessária a definição da vazão disponível para alocação aos usuários, obtida a partir da vazão de referência, utilizada como base para o processo de gestão dos recursos hídricos. Em Goiás, a Resolução $N^{o} 11$, de 20 de março de 2007, aprovada pelo Conselho Estadual de Recursos Hídricos, determina a adoção da vazão com garantia de permanência em $95 \%$ do tempo $\left(\mathrm{Q}_{95}\right)$ como vazão de referência e a porção de $50 \%$ dessa como vazão alocável. Isso não exclui, porém, a necessidade de conhecimento de outras vazões para o planejamento de obras e outras atividades de gestão (Arnéz, 2002). Decisões tomadas a partir de informações de vazão pouco representativas podem comprometer a gestão e o planejamento de recursos hídricos.

A determinação da disponibilidade hídrica necessita de monitoramento contínuo e a realização de estudos complementares. Esse conhecimento é obtido, preferencialmente, de dados históricos de vazões dos mananciais. A implantação de postos de medição de vazão em número e localização suficientes para a representação do comportamento fluviométrico de uma área, no entanto, nem sempre é um procedimento viável pelo alto custo envolvido e pela falta de recursos disponíveis.

A maioria das bacias hidrográficas não dispõe de dados fluviométricos suficientes. Silveira e Tucci (1998), ao desenvolverem estudo para a quantificação de vazão em pequenas bacias hidrográficas, constataram que a atual rede hidrometeorológica brasileira contempla as grandes bacias hidrográficas, com áreas maiores que $500 \mathrm{~km}^{2}$, e que as pequenas bacias, com áreas de drenagem inferiores a $100 \mathrm{~km}^{2}$, apresentam carência quase total de dados. Os mesmos autores afirmam, ainda, que a carência de dados fluviométricos leva a grandes incertezas na avaliação quantitativa dos recursos hídricos.

A escassez de dados históricos torna necessária a busca por soluções alternativas que levem ao conhecimento da disponibilidade hídrica das bacias hidrográficas. Segundo Silva Júnior (2001), devido à escassez de dados em pequenas bacias, suas variáveis hidrológicas são obtidas pela transferência de informações hidrológicas de grandes bacias, que, normalmente, têm maior disponibilidade de dados hidrológicos. Isso é alcançado pelo procedimento de regionalização de vazões, que permite a transferência de dados fluviométricos de um local para outro hidrologicamente semelhante, baseando-se nas relações de homogeneidade entre as regiões (Tucci, 2004). Obregon et al. (1999), estudando as séries de vazão estendidas para a regionalização, afirmam que, em bacias com carência de dados 
FIOREZE, A. P.; OliveIRA, L. F. C.; FRANCO, A. P. B. Avaliação do desempenho de equações de regionalização de vazões na bacia hidrográfica do Ribeirão Santa Bárbara, Goiás, Brasil. Ambi-Agua, Taubaté, v. 3, n. 2, p. 62-76, 2008. (doi:10.4136/ambi-agua.53)

hidrológicos, a regionalização de vazões constitui um procedimento muito valioso para a avaliação dos recursos hídricos.

O emprego das equações de regionalização deve ser efetuado somente quando houver segurança quanto ao seu desempenho em refletir o comportamento hidrológico da bacia. Sugai et al. (1998) encontraram discrepâncias de 3 a 75\% para a $Q_{95}$ ao comparar os valores estimados por equações de regionalização com valores obtidos de dados observados em bacias hidrográficas do Estado do Paraná.

As principais incertezas na determinação da disponibilidade hídrica de uma bacia provêm das amostras das informações, dos dados de entrada e saída do modelo, da estrutura e dos parâmetros do modelo (Cruz, 2001). Isso decorre do fato de que os modelos são uma representação simplificada da natureza, na qual há perda de informações. Assani et al. (2006) procuraram, com o método de regionalização que denominaram "eco-geográfico", incorporar outras características do escoamento de maior interesse à ecologia e que envolvessem fatores ambientais. No entanto, pela dificuldade de obtenção dessas informações, a maioria dos modelos disponíveis não incorpora, por exemplo, as variações existentes pela ação humana na bacia hidrográfica, que altera drasticamente as condições de infiltração e escoamento das precipitações. Normalmente, os parâmetros empregados nos modelos de regionalização de vazões dizem respeito a condições de clima e características fisiográficas das bacias. Alterach et al. (2006), ao avaliarem procedimentos para regionalização de vazões diárias na região dos Alpes italianos, concluíram que, entre os parâmetros empregados, os mais significativos foram: a área de drenagem, a precipitação média anual, o comprimento do rio principal, o relevo da bacia e a percentagem de área impermeável.

Para a validação de equações de regionalização, é importante a comparação dos resultados estimados com as vazões de saída da área onde se pretende aplicá-las. Cruz (2001) afirma que a disponibilidade de monitoramento em pequenas bacias permite avaliar o grau de confiabilidade da extrapolação e a validação de estudos de regionalização para toda a bacia onde é desenvolvido. Laaha e Blöschl (2006) empregaram dados de 325 sub-bacias monitoradas para avaliar o desempenho de diferentes métodos de regionalização.

Apesar de algumas limitações no emprego da regionalização de vazões, a técnica vem sendo amplamente empregada na obtenção de disponibilidade hídrica em bacias não monitoradas ou com registros insuficientes em todo o mundo. Parajka et al. (2005) compararam diferentes métodos de regionalização de parâmetros hidrológicos para bacias hidrográficas na Áustria, com área variando de $10 \mathrm{~km}^{2}$ a $9770 \mathrm{~km}^{2}$ e diversas condições de relevo, precipitação e uso do solo, obtendo bom desempenho no método baseado na definição de regiões homogêneas e na similaridade das características fisiográficas das bacias. Massuel e Cappelaere (2005) empregaram séries com registros de nove anos em bacias hidrográficas nigerianas para desenvolver modelos de previsão de vazões resultantes de precipitações.

No Estado de Minas Gerais, um programa de regionalização hidrológica, denominado RH 3.0, foi empregado para $96 \%$ do território. O mesmo procedimento foi empregado na subbacia do Rio Purus, que pertence à bacia do Rio Amazonas, e vem sendo aplicado como apoio à elaboração de diferentes Planos Diretores de Recursos Hídricos (UFV, 2004). Euclydes et al. (2002), em um trabalho de regionalização no Alto São Francisco, obtiveram resultados razoáveis para vazões mínimas com duração de sete dias e dez anos de período de retorno.

No Estado de Goiás, foram realizados estudos de regionalização de vazões para a bacia hidrográfica do Rio Meia Ponte (Rusteberg, 2003), como parte do Convênio de Cooperação Técnica Brasil-Alemanha, que pretendia fornecer subsídios à gestão daquela bacia. O extinto Ministério da Irrigação produziu modelos de regionalização de vazões mensais para o sudoeste goiano (Brasil, 1987) e Cortês (2004) obteve modelos de regionalização das vazões mínima, média, máxima e $\mathrm{Q}_{95}$ para a bacia hidrográfica do Rio dos Bois. Os modelos gerados 
FIOREZE, A. P.; OLIVEIRA, L. F. C.; FRANCO, A. P. B. Avaliação do desempenho de equações de regionalização de vazões na bacia hidrográfica do Ribeirão Santa Bárbara, Goiás, Brasil. Ambi-Agua, Taubaté, v. 3, n. 2, p. 62-76, 2008. (doi:10.4136/ambi-agua.53)

em ambos os trabalhos não foram avaliados para pequenas sub-bacias, como é o caso da bacia do Ribeirão Santa Bárbara. Assim, não é possível afirmar definitivamente que as estimativas obtidas a partir desses modelos possam ser empregadas de maneira confiável em toda a extensão da bacia.

Este trabalho teve como objetivo a avaliação do desempenho das equações de regionalização de vazões conhecidas para a região da bacia hidrográfica do Ribeirão Santa Bárbara, em Goiás, a partir da caracterização do seu comportamento hidrológico.

\section{MATERIAL E MÉTODOS}

\subsection{Caracterização da bacia hidrográfica do Ribeirão Santa Bárbara}

A bacia hidrográfica do Ribeirão Santa Bárbara está localizada na região sul do Estado de Goiás e pertence à bacia do Rio dos Bois, que, por sua vez, pertence à bacia hidrográfica do Rio Paranaíba. A bacia hidrográfica do Ribeirão Santa Bárbara, representada na Figura 1, está compreendida entre as coordenadas $17^{\circ} 45^{\prime}$ e $18^{\circ} 15^{\prime}$ de latitude sul e $49^{\circ} 36^{\prime}$ e $50^{\circ} 03^{\prime}$ de longitude oeste, na região centro-sul de Goiás. A área da bacia inclui os municípios de Vicentinópolis, Joviânia, Goiatuba e Bom Jesus de Goiás. O exutório da área de estudo, delimitada pela estação Fazenda Aliança, está localizado a $15 \mathrm{~km}$ à montante da foz do Ribeirão Santa Bárbara, em uma altitude aproximada de 452 metros (Figura 2).

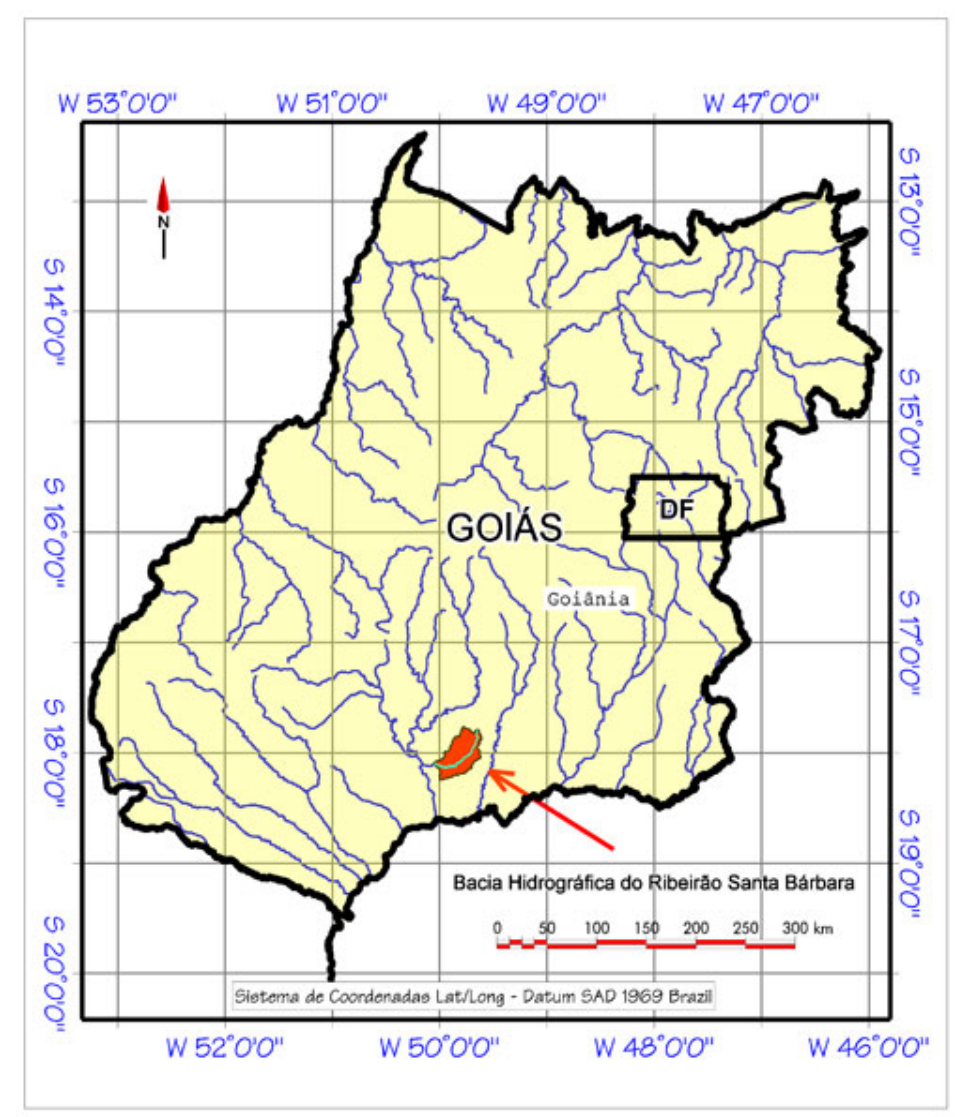

Figura 1. Bacia hidrográfica do Ribeirão Santa Bárbara, Goiás (Franco, 2006).

As características físicas empregadas nas equações de regionalização de vazões foram: (a) área de drenagem, (b) comprimento do curso de água principal, (c) densidade de drenagem, (d) coeficiente de compacidade e (e) declividade do álveo. Essas características 
FIOREZE, A. P.; OliveIRA, L. F. C.; FRANCO, A. P. B. Avaliação do desempenho de equações de regionalização de vazões na bacia hidrográfica do Ribeirão Santa Bárbara, Goiás, Brasil. Ambi-Agua, Taubaté, v. 3, n. 2, p. 62-76, 2008. (doi:10.4136/ambi-agua.53)

foram obtidas conforme metodologia descrita por Villela e Mattos (1975), a partir da base topográfica do Instituto Brasileiro de Geografia e Estatística (IBGE), em escala 1:100.000, da superfície de relevo gerada por imagens SRTM (Shuttle Radar Topography Mission) e do sensor TM+ a bordo do satélite Landsat 7. Todas as informações foram processadas em um Sistema de Informações Geográficas (SIG) denominado TNT mips (map image processing system), que contém ferramenta específica para trabalhar com pequenas bacias hidrográficas.

A precipitação média na bacia hidrográfica foi obtida pelo método de Thiessen, empregando as precipitações totais anuais das estações pluviométricas Fazenda Aliança, Joviânia, Ponte Sul Goiana, Maurilândia e Ponte Meia Ponte (Figura 2). Empregaram-se, nesse estudo, as séries históricas consistidas disponíveis no sistema de informações da Agência Nacional de Águas, com 31 a 34 anos de observações no período de 1971 a 2004.

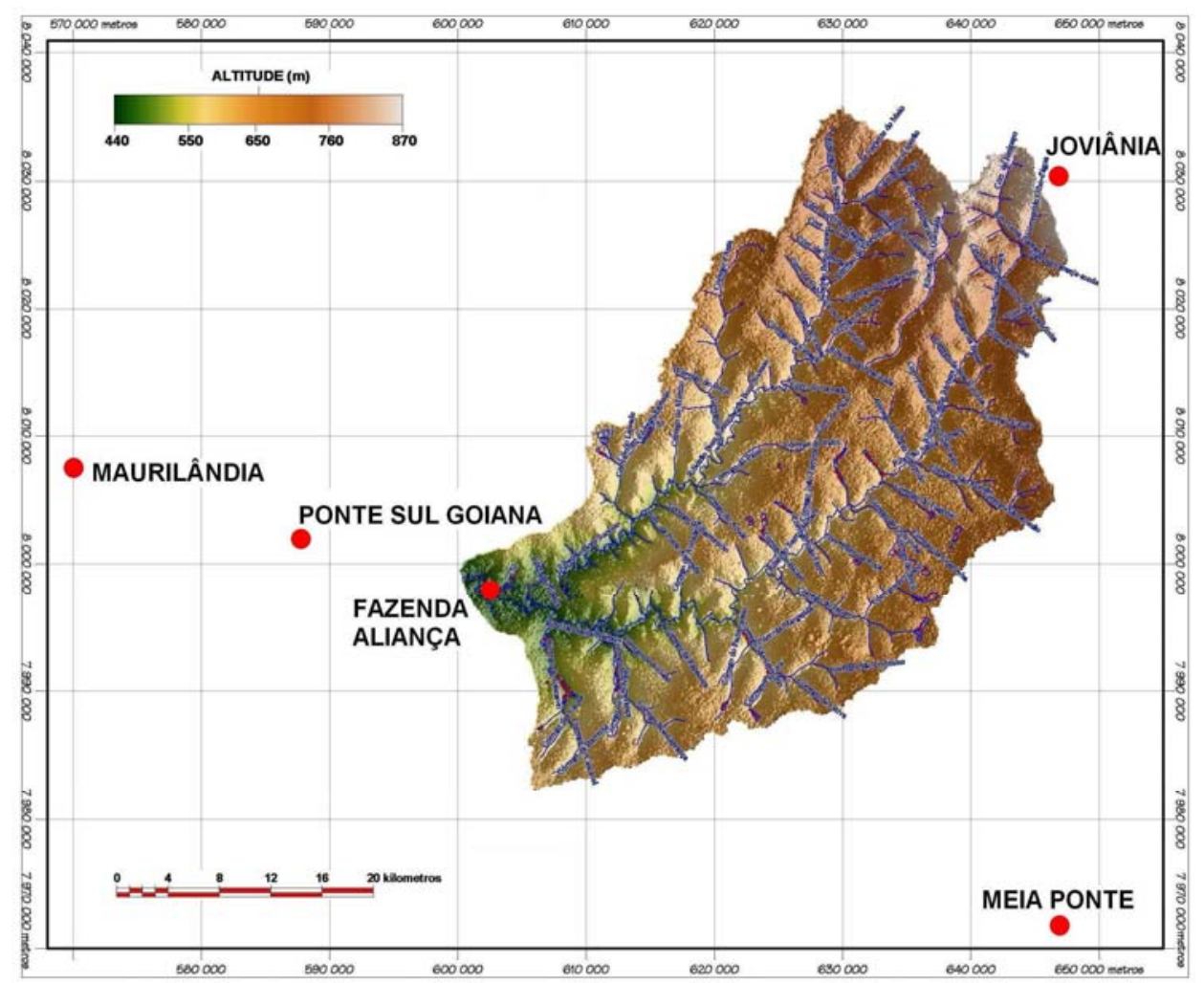

Figura 2. Relevo, topografia e estações pluviométricas empregadas, bacia hidrográfica do Ribeirão Santa Bárbara, Goiás (Franco, 2006).

As vazões de saída da bacia hidrográfica do Ribeirão Santa Bárbara correspondem àquelas observadas na estação fluviométrica denominada Fazenda Aliança, que limita a área da bacia em estudo (Figura 2). A série disponível no sistema de informações da Agência Nacional de Águas é constituída de dados consistidos de vazões diárias, observadas no período de 1969 a 2004. Com base na série histórica, foram calculadas a vazão média de longo período ( $\left.\mathrm{Q}_{\mathrm{MLP}}\right)$, a vazão mínima ( $\left.\mathrm{Q}_{\mathrm{MIN}}\right)$, a vazão máxima ( $\left.\mathrm{Q}_{\mathrm{MAX}}\right)$ e a vazão com $95 \%$ de permanência $\left(Q_{95}\right)$, a vazão mínima com sete dias de duração e dez anos de tempo de retorno $\left(Q_{7,10}\right)$ e as vazões médias mensais.

A $Q_{M L P}$ foi obtida pela média aritmética de todas as vazões diárias observadas. As vazões médias mensais para todo o período de dados disponível foram obtidas a partir da construção de uma série de vazões médias mensais a cada ano. A $\mathrm{Q}_{\mathrm{MIN}}$ corresponde à média das vazões observadas em uma série construída com as vazões mínimas com duração de sete dias a cada

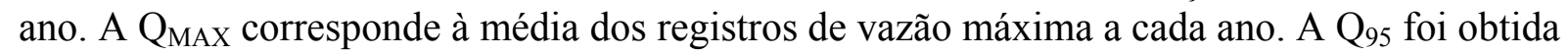


pela confecção da curva de permanência de vazões. A curva de permanência corresponde à freqüência acumulada das vazões observadas, dispostas em ordem decrescente em classes.

A $\mathrm{Q}_{7,10}$ foi calculada a partir da construção da série de vazões médias das mínimas com sete dias de duração. Empregando-se a distribuição log-normal à série produzida, foi possível calcular o valor correspondente ao tempo de retorno de dez anos.

As vazões $\mathrm{Q}_{\mathrm{MLP}}, \mathrm{Q}_{\mathrm{MIN}}, \mathrm{Q}_{\mathrm{MAX}}$ e $\mathrm{Q}_{95}$ foram também calculadas para cada ano no qual se dispunha de dados pluviométricos coincidentes (1974 a 1996), de forma a possibilitar a calibração das equações geradas por Cortês (2004) que têm a precipitação pluviométrica média como uma das variáveis explicativas.

\subsection{Aplicação e avaliação do desempenho das equações de regionalização de vazões}

As equações de regionalização de vazão empregadas neste trabalho foram aquelas ajustadas por Cortês (2004) e pelo Proni (Brasil, 1987). As equações do Proni (Brasil, 1987) regionalizam, com base na área de drenagem e para cinco zonas homogêneas definidas, as vazões média de longo período, mínima média de sete dias consecutivos com tempo de retorno de dez anos $\left(\mathrm{Q}_{7,10}\right)$ e médias mensais para as bacias hidrográficas do Rio dos Bois ao Rio Corrente. As equações de Cortês foram geradas empregando sub-bacias com área de drenagem entre 557 e $17.245 \mathrm{~km}^{2}$ para estimar as vazões mínima, média, máxima e a vazão com 95\% de permanência na bacia hidrográfica do Rio dos Bois, com base em até seis variáveis explicativas. As equações são válidas para áreas de drenagem compreendidas no intervalo correspondente àquele das sub-bacias utilizadas no ajuste. As equações produzidas por Cortês (2004), com seis, cinco, duas e uma variáveis independentes, e pelo Proni (Brasil, 1987), com uma variável independente, estão apresentadas na Tabela 1.

Para verificar a adequacidade das estimativas empregando as equações de regionalização de vazão geradas por Cortês (2004) e pelo Proni (Brasil, 1987), foi realizada a comparação com os valores observados na estação fluviométrica Fazenda Aliança. Para tal, empregou-se o erro relativo em cada estimativa, descrito pela equação:

$$
E R=\frac{\hat{Q}-Q}{Q}
$$

em que:

$\mathrm{ER}=$ erro relativo da estimativa;

$\hat{Q}=$ vazão estimada pela equação, em $\mathrm{m}^{3} \mathrm{~s}^{-1}$;

$Q=$ vazão observada, em $\mathrm{m}^{3} \mathrm{~s}^{-1}$.

As equações que envolvem a precipitação média como uma das variáveis independentes (equações $1,2,5,6,9,10,13$ e 14) tiveram sua precisão avaliada pelo coeficiente de correlação r e pelo índice de concordância de Willmott, dado por:

$$
d=1-\frac{\sum_{i=1}^{n}\left(\hat{Q}_{i}-Q_{i}\right)^{2}}{\sum_{i=1}^{n}\left(\hat{Q}_{i}^{\prime}|+| Q_{i}^{\prime} \mid\right)^{2}}
$$

sendo:

$$
\hat{Q_{i}^{\prime}}=\hat{Q_{i}}-\bar{Q} ; Q_{i}^{\prime}=Q_{i}-\bar{Q}
$$

em que:

$d=$ índice de concordância de Willmott;

$\bar{Q}=$ média das vazões observadas, em $\mathrm{m}^{3} \mathrm{~s}^{-1}$. 
FIOREZE, A. P.; OliveIRA, L. F. C.; FRANCO, A. P. B. Avaliação do desempenho de equações de regionalização de vazões na bacia hidrográfica do Ribeirão Santa Bárbara, Goiás, Brasil. Ambi-Agua, Taubaté, v. 3, n. 2, p. 62-76, 2008. (doi:10.4136/ambi-agua.53)

Tabela 1. Equações de regionalização de vazões $\left(\mathrm{m}^{3} \mathrm{~s}^{-1}\right)$ ajustadas por Cortês (2004) e pelo Proni (Brasil, 1987) para a região da bacia hidrográfica do Ribeirão Santa Bárbara, Goiás.

\begin{tabular}{|c|c|c|}
\hline \multirow{2}{*}{ Autor } & \multicolumn{2}{|l|}{ Equação } \\
\hline & $\mathrm{Q}_{\mathrm{MIN}}=15,617 \mathrm{~A}^{-0,03223} \mathrm{~L}^{2,5902} \mathrm{Dd}^{-4,2992} \mathrm{D}^{1,5923} \mathrm{P}^{-1,7577} \mathrm{Kc}^{-2,0607}$ & [1] \\
\hline \multirow{15}{*}{ Cortês (2004) } & $\mathrm{Q}_{\mathrm{MIN}}=1,0324 \times 10^{5} \mathrm{~A}^{0,894} \mathrm{Dd}^{-3,8784} \mathrm{D}^{0,03145} \mathrm{P}^{-2,5809} \mathrm{Kc}^{-0,3319}$ & [2] \\
\hline & $\mathrm{Q}_{\mathrm{MIN}}=7,8822 \times 10^{-4} \mathrm{~A}^{0,9107} \mathrm{Dd}^{-3,3181}$ & [3] \\
\hline & $\mathrm{Q}_{\mathrm{MIN}}=3,8812 \times 10^{-2} \mathrm{~A}^{0,7767}$ & [4] \\
\hline & $\mathrm{Q}_{\mathrm{MLP}}=7,3417 \times 10^{4} \mathrm{~A}^{0,39529} \mathrm{~L}^{1,1972} \mathrm{Dd}^{-2,3149} \mathrm{D}^{0,5344} \mathrm{P}^{-2,3283} \mathrm{Kc}^{-1,4494}$ & [5] \\
\hline & $\mathrm{Q}_{\mathrm{MLP}}=4,2804 \times 10^{6} \mathrm{~A}^{0,8234} \mathrm{Dd}^{-2,1204} \mathrm{D}^{-0,1869} \mathrm{P}^{-2,7087} \mathrm{Kc}^{-0,6503}$ & [6] \\
\hline & $\mathrm{Q}_{\mathrm{MLP}}=8,1165 \times 10^{-3} \mathrm{~A}^{0,9159} \mathrm{Dd}^{-1,6507}$ & [7] \\
\hline & $\mathrm{Q}_{\mathrm{MLP}}=5,6397 \times 10^{-2} \mathrm{~A}^{0,84945}$ & [8] \\
\hline & $\mathrm{Q}_{\text {MAX }}=2,31 \times 10^{10} \mathrm{~A}^{0,36932} \mathrm{~L}^{1,2839} \mathrm{Dd}^{-3,3483} \mathrm{D}^{0,76312} \mathrm{P}^{-3,9507} \mathrm{Kc}^{-1,7450}$ & [9] \\
\hline & $\mathrm{Q}_{\mathrm{MAX}}=1,8 \times 10^{12} \mathrm{~A}^{0,8284} \mathrm{Dd}^{-3,1398} \mathrm{D}^{-0,01052} \mathrm{P}^{-4,3587} \mathrm{Kc}^{-0,8881}$ & [10] \\
\hline & $\mathrm{Q}_{\text {MAX }}=3,0619 \times 10^{-2} \mathrm{~A}^{0,8805} \mathrm{Dd}^{-2,0813}$ & [11] \\
\hline & $\mathrm{Q}_{\mathrm{MAX}}=3,528 \times 10^{-1} \mathrm{~A}^{0,79664}$ & [12] \\
\hline & $\mathrm{Q}_{95}=1,7257 \mathrm{~A}^{-0,16792} \mathrm{~L}^{2,9094} \mathrm{Dd}^{-4,2920} \mathrm{D}^{1,7083} \mathrm{P}^{-1,4968} \mathrm{Kc}^{-2,2436}$ & [13] \\
\hline & $\mathrm{Q}_{95}=3,3721 \times 10^{4} \mathrm{~A}^{0,8724} \mathrm{Dd}^{-3,8193} \mathrm{D}^{-0,04479} \mathrm{P}^{-2,4214} \mathrm{Kc}^{-0,3019}$ & [14] \\
\hline & $\mathrm{Q}_{95}=6,9924 \times 10^{-4} \mathrm{~A}^{0,9124} \mathrm{Dd}^{-3,4016}$ & [15] \\
\hline & $\mathrm{Q}_{95}=3,80 \times 10^{-2} \mathrm{~A}^{0,77533}$ & [16] \\
\hline \multirow{14}{*}{ Proni (1987) } & $\mathrm{Q}_{\mathrm{MLP}}=1,172 \times 10^{-2} \mathrm{~A}^{0,9684}$ & [17] \\
\hline & $\mathrm{Q}_{7,10}=2,9 \times 10^{-3} \mathrm{~A}^{0,9541}$ & [18] \\
\hline & Jan $\quad \mathrm{Q}_{\mathrm{MED}}=2,02 \times 10^{-2} \mathrm{~A}^{1,0007}$ & [19] \\
\hline & Fev $\quad Q_{M E D}=1,52 \times 10^{-2} \mathrm{~A}^{1,0410}$ & [20] \\
\hline & Mar $\quad Q_{M E D}=2,48 \times 10^{-2} A^{0,9858}$ & [21] \\
\hline & Abr $\quad \mathrm{Q}_{\mathrm{MED}}=2,77 \times 10^{-2} \mathrm{~A}^{0,9557}$ & [22] \\
\hline & Mai $\quad \mathrm{Q}_{\mathrm{MED}}=4,07 \times 10^{-2} \mathrm{~A}^{0,8698}$ & [23] \\
\hline & Jun $\quad Q_{M E D}=3,62 \times 10^{-2} A^{0,8576}$ & [24] \\
\hline & Jul $\quad Q_{M E D}=3,13 \times 10^{-2} A^{0,8492}$ & [25] \\
\hline & Ago $\quad Q_{M E D}=2,40 \times 10^{-2} A^{0,8558}$ & [26] \\
\hline & Set $\mathrm{Q}_{\mathrm{MED}}=1,87 \times 10^{-2} \mathrm{~A}^{0,8723}$ & {$[27]$} \\
\hline & Out $\quad \mathrm{Q}_{\mathrm{MED}}=1,51 \times 10^{-2} \mathrm{~A}^{0,9094}$ & [28] \\
\hline & Nov $Q_{M E D}=1,79 \times 10^{-2} A^{0,9395}$ & [29] \\
\hline & Dez $\quad \mathrm{Q}_{\mathrm{MED}}=1,74 \times 10^{-2} \mathrm{~A}^{0,9846}$ & [30] \\
\hline
\end{tabular}

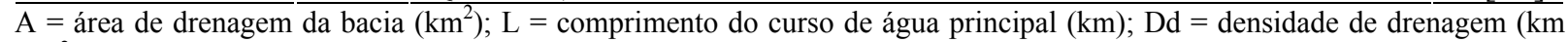
$\left.\mathrm{km}^{-2}\right) ; \mathrm{D}=$ declividade do curso de água principal (\%); $\mathrm{P}=$ precipitação pluviométrica média anual (mm) e Kc = coeficiente de compacidade.

Outro índice utilizado para avaliar o desempenho das equações que envolvem a precipitação média como variável independente foi o índice $c$, proposto por Camargo e Sentelhas (1997 apud Medeiros, 2002). O índice c é obtido pelo produto do coeficiente de correlação $(r)$ pelo índice de concordância de Willmott $(d)$ e classifica o desempenho das equações conforme a Tabela 2 . 
FIOREZE, A. P.; OliveIRA, L. F. C.; FRANCO, A. P. B. Avaliação do desempenho de equações de regionalização de vazões na bacia hidrográfica do Ribeirão Santa Bárbara, Goiás, Brasil. Ambi-Agua, Taubaté, v. 3, n. 2, p. 62-76, 2008. (doi:10.4136/ambi-agua.53)

Tabela 2. Desempenho das equações de regionalização de vazão pelo índice $c$.

\begin{tabular}{cc}
\hline Valor de $c$ & Desempenho \\
\hline$>0,90$ & Ótimo \\
0,81 a 0,90 & Muito bom \\
0,71 a 0,80 & Bom \\
0,51 a 0,70 & Mediano \\
0,41 a 0,50 & Sofrível \\
0,31 a 0,40 & Mau \\
$\leq 0,30$ & Péssimo \\
\hline
\end{tabular}

Fonte: Medeiros (2002).

\section{RESULTADOS E DISCUSSÃO}

\subsection{Caracterização da bacia hidrográfica do Ribeirão Santa Bárbara}

A bacia hidrográfica do Ribeirão Santa Bárbara apresenta área de drenagem de 1371,16 $\mathrm{km}^{2}$, comprimento do curso de água principal de $96,88 \mathrm{~km}$, densidade de drenagem de 0,56 $\mathrm{km} \mathrm{km}^{-2}$, coeficiente de compacidade de 1,53 e declividade do álveo de $0,38 \%$.

A distribuição da precipitação é desigual durante o ano e se caracteriza pela existência de verões chuvosos e invernos secos, conforme precipitação média mensal ocorrida na estação Fazenda Aliança, localizada na bacia. $\mathrm{O}$ ano hidrológico estende-se de outubro a setembro, com precipitação próxima a zero nos meses de junho a agosto. A precipitação pluviométrica média anual na bacia hidrográfica do Ribeirão Santa Bárbara, obtida pelo emprego dos polígonos de Thiessen, foi de $1510,1 \mathrm{~mm}$.

A vazão média de longo período $\left(\mathrm{Q}_{\mathrm{MLP}}\right)$, máxima $\left(\mathrm{Q}_{\mathrm{MAX}}\right)$ e média das mínimas com sete dias de duração (Q $\left.\mathrm{Q}_{\mathrm{MIN}}\right)$ foram de 19,70; 76,17 e 7,04 $\mathrm{m}^{3} \mathrm{~s}^{-1}$, respectivamente. A vazão com $95 \%$ de permanência $\left(\mathrm{Q}_{95}\right)$ obtida a partir da construção da curva de permanência (Figura 3) corresponde a $4,20 \mathrm{~m}^{3} \mathrm{~s}^{-1}$.

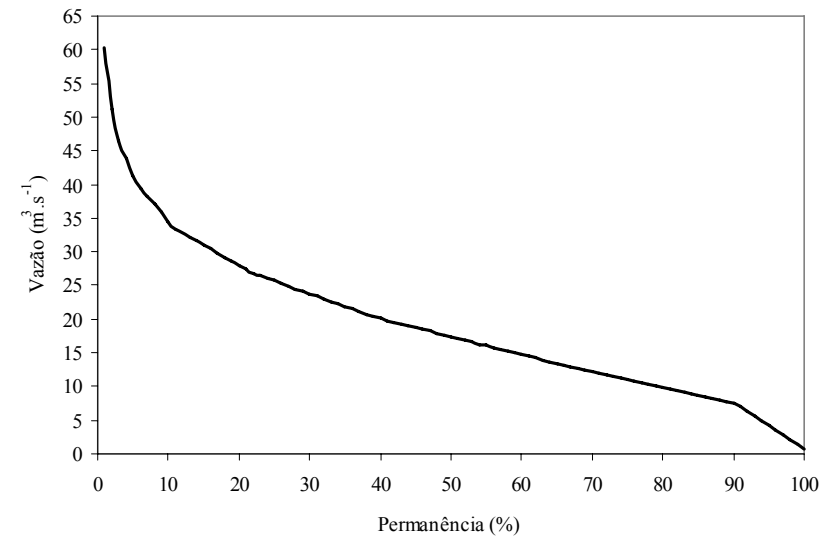

Figura 3. Curva de permanência das vazões do Ribeirão Santa Bárbara na estação Fazenda Aliança, 1969 a 2004, bacia hidrográfica do Ribeirão Santa Bárbara, Goiás.

Segundo Barbosa et al. (2005), a vazão média de longo período indica a disponibilidade hídrica na bacia e representa a máxima vazão teoricamente possível de ser regularizada pela construção de reservatório. As vazões mínimas representam a disponibilidade natural da bacia e a vazão máxima está associada a riscos de inundação e a projetos de obras hidráulicas.

As vazões mínimas e máximas não foram, a princípio, associadas a uma freqüência de ocorrência. Tal medida foi adotada para que fosse seguido o método utilizado por Cortês 
FIOREZE, A. P.; OliveIRA, L. F. C.; FRANCO, A. P. B. Avaliação do desempenho de equações de regionalização de vazões na bacia hidrográfica do Ribeirão Santa Bárbara, Goiás, Brasil. Ambi-Agua, Taubaté, v. 3, n. 2, p. 62-76, 2008. (doi:10.4136/ambi-agua.53)

(2004), de maneira a possibilitar a avaliação do desempenho das equações de regionalização propostas pelo autor. Os mesmos procedimentos foram adotados para cada ano, gerando-se uma série de vazões mínimas com sete dias de duração e uma série de vazões máximas.

A vazão mínima observada foi maior que a $Q_{95}$ por se tratar somente da média das vazões mínimas médias em sete dias consecutivos, não associada a risco de ocorrência. Dessa forma, os anos de vazões elevadas contribuem tanto quanto aqueles com menores vazões, mais próximos de uma situação crítica.

Normalmente, a vazão mínima corresponde ao evento mínimo observado ou está associada a um determinado risco de ocorrência, resultando valor inferior à vazão com $95 \%$ de permanência. Para Tucci (2004), a determinação de vazões mínimas com uma determinada duração é mais interessante, já que a seqüência de vazões baixas é a condição mais crítica na utilização da água. A curva de probabilidade de vazões mínimas permite estimar o risco de que ocorram. A vazão mínima com sete dias de duração e dez anos de tempo de retorno $\left(\mathrm{Q}_{7,10}\right)$ na bacia do Ribeirão Santa Bárbara foi de $1,08 \mathrm{~m}^{3} \mathrm{~s}^{-1}$. A $\mathrm{Q}_{7,10}$ indica as vazões críticas de estiagem e é muito empregada para projetos de abastecimento público por representar o risco aceitável para esse tipo de captação. A exemplo do que foi encontrado por Rusteberg (2003) para a bacia hidrográfica do Rio Meia Ponte, em Goiás, na bacia do Ribeirão Santa Bárbara a $\mathrm{Q}_{7,10}$ se aproxima da vazão com $99 \%$ de permanência $\left(\mathrm{Q}_{99}\right)$.

As vazões médias mensais refletem o regime de precipitação observado na bacia, conforme demonstrado na Figura 4. O início do período de estiagem, no mês de abril, marca o início da redução das vazões de saída na bacia hidrográfica do Ribeirão Santa Bárbara, que diminuem até que se iniciam as chuvas, no mês de outubro.
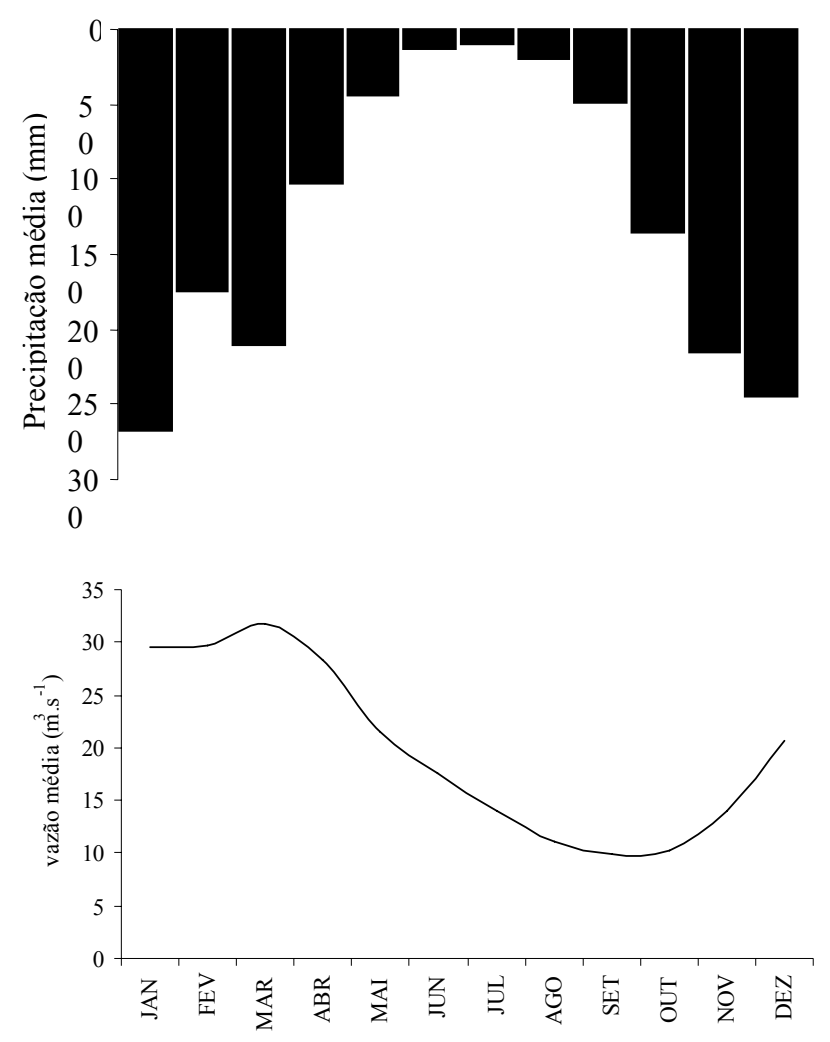

Figura 4. Precipitação média mensal e hidrograma de vazões de saída correspondente na bacia hidrográfica do Ribeirão Santa Bárbara, Goiás. 
FIOREZE, A. P.; OLIVEIRA, L. F. C.; FRANCO, A. P. B. Avaliação do desempenho de equações de regionalização de vazões na bacia hidrográfica do Ribeirão Santa Bárbara, Goiás, Brasil. Ambi-Agua, Taubaté, v. 3, n. 2, p. 62-76, 2008. (doi:10.4136/ambi-agua.53)

\subsection{Aplicação e avaliação do desempenho das equações de regionalização de vazões}

As equações de 1 a 30 (Tabela 1), ajustadas por Cortês (2004) e Proni (Brasill, 1987), tiveram seu desempenho avaliado em comparação com as vazões observadas na estação Fazenda Aliança, na série disponível, de 1969 a 2004. Inicialmente, a avaliação do desempenho considerou somente o desvio dos resultados estimados pelas equações em comparação com os resultados observados, visto que, para a maioria das equações, somente é possível obter um resultado, já que as variáveis independentes envolvidas são únicas para a bacia.

As equações ajustadas por Cortês (2004) tiveram, em média, desempenho inferior àquelas ajustadas pelo Proni (Brasil, 1987) como evidenciam os resultados dos erros relativos obtidos (Tabela 3). No entanto, comparando-se o único valor estimado por ambos os autores, a Q QLP, observa-se que o melhor resultado foi obtido pelo emprego de uma das equações ajustadas por Cortês (Equação 7). Ainda, o maior erro observado foi referente à estimativa da $\mathrm{Q}_{7,10}$, pela equação 18, ajustada por Proni (Brasil, 1987).

Tabela 3. Vazões de referência observadas e estimadas pelas equações de regionalização de vazão ajustadas por Cortês (2004) e Proni (Brasil, 1987), na bacia hidrográfica do Ribeirão Santa Bárbara, Goiás.

\begin{tabular}{|c|c|c|c|c|c|}
\hline Vazão & Obser & $\left.\mathrm{m}^{3} \mathrm{~s}^{-1}\right)$ & Equação & Estimado $\left(\mathrm{m}^{3} \mathrm{~s}^{-1}\right)$ & Erro (\%) \\
\hline \multirow{4}{*}{$\mathrm{Q}_{\text {MíN }}$} & \multirow{4}{*}{\multicolumn{2}{|c|}{7,04}} & 1 & 5,01 & $-28,87$ \\
\hline & & & 2 & 3,36 & $-52,24$ \\
\hline & & & 3 & 3,97 & $-43,64$ \\
\hline & & & 4 & 10,61 & 50,65 \\
\hline \multirow{5}{*}{$\mathrm{Q}_{\mathrm{MLP}}$} & \multirow{5}{*}{\multicolumn{2}{|c|}{19,7}} & 5 & 15,14 & $-23,13$ \\
\hline & & & 6 & 12,60 & $-36,03$ \\
\hline & & & 7 & 15,96 & $-18,99$ \\
\hline & & & 8 & 26,06 & 32,31 \\
\hline & & & 17 & 12,79 & $-35,07$ \\
\hline \multirow{4}{*}{$Q_{\text {MÁx }}$} & \multirow{4}{*}{\multicolumn{2}{|c|}{76,17}} & 9 & 53,01 & $-30,41$ \\
\hline & & & 10 & 43,32 & $-43,13$ \\
\hline & & & 11 & 60,01 & $-21,22$ \\
\hline & & & 12 & 111,34 & 46,18 \\
\hline \multirow{4}{*}{$\mathrm{Q}_{95}$} & \multirow{4}{*}{\multicolumn{2}{|c|}{4,20}} & 13 & 4,97 & 18,43 \\
\hline & & & 14 & 3,18 & $-24,33$ \\
\hline & & & 15 & 3,74 & $-10,90$ \\
\hline & & & 16 & 10,28 & 144,80 \\
\hline $\mathrm{Q}_{7,10}$ & \multicolumn{2}{|c|}{1,082} & 18 & 2,85 & 163,79 \\
\hline \multirow{12}{*}{$\begin{array}{l}\text { Q médias } \\
\text { mensais }\end{array}$} & Jan & 29,50 & 19 & 27,84 & $-2,32$ \\
\hline & $\mathrm{Fev}$ & 29,63 & 20 & 28,03 & $-5,40$ \\
\hline & Mar & 31,79 & 21 & 30,69 & $-3,48$ \\
\hline & Abr & 28,26 & 22 & 27,58 & $-2,40$ \\
\hline & Mai & 21,57 & 23 & 21,79 & 1,03 \\
\hline & Jun & 17,56 & 24 & 17,74 & 1,05 \\
\hline & Jul & 14,02 & 25 & 14,44 & 2,98 \\
\hline & Ago & 11,16 & 26 & 11,61 & 4,04 \\
\hline & Set & 9,85 & 27 & 10,19 & 3,51 \\
\hline & Out & 10,17 & 28 & 10,76 & 5,86 \\
\hline & Nov & 14,07 & 29 & 15,85 & 12,71 \\
\hline & Dez & 20,72 & 30 & 21,35 & 3,04 \\
\hline
\end{tabular}


FIOREZE, A. P.; OLIVEIRA, L. F. C.; FRANCO, A. P. B. Avaliação do desempenho de equações de regionalização de vazões na bacia hidrográfica do Ribeirão Santa Bárbara, Goiás, Brasil. Ambi-Agua, Taubaté, v. 3, n. 2, p. 62-76, 2008. (doi:10.4136/ambi-agua.53)

É possível que o desempenho geral superior das equações produzidas por Proni (Brasil, 1987) se deva ao fato de ter havido, para este trabalho, a identificação e delimitação de zonas homogêneas dentro da região estudada. As equações de regionalização de vazão foram propostas para cada uma das zonas homogêneas. O trabalho de Cortês (2004), por sua vez, propõe equações que abrangem todo o território da bacia hidrográfica do Rio dos Bois. Ao efetuarem regionalizações de vazões no Estado de Minas Gerais, Euclydes (2005) e Barbosa et al. (2005) caracterizaram as regiões homogêneas por meio de critérios físicos e estatísticos, baseados nas características fisiográficas e na distribuição de freqüências das vazões adimensionalizadas em relação à vazão média de longa duração.

A redução do número de variáveis explicativas normalmente leva à redução do desempenho das equações, o que não foi observado neste estudo. Entre as equações ajustadas por Cortês (2004), tiveram melhor desempenho pelo coeficiente de Wilmont aquelas que relacionaram a vazão com a área da bacia hidrográfica e a densidade de drenagem. Exceção foi percebida nas equações para determinação da QMíN, em que a equação com melhor desempenho é aquela que envolve todas as variáveis independentes. Já as equações que utilizam somente a área como variável explicativa produziram resultados com desvios elevados em relação ao observado. Os maiores desvios encontrados estão na estimativa das vazões mínimas ( $\left.\mathrm{Q}_{\mathrm{MIN}} \mathrm{e} \mathrm{Q}_{95}\right)$ em função somente da área de drenagem.

A vazão máxima, reflexo direto da precipitação na bacia, cuja estimativa deveria ser afetada negativamente pela retirada da precipitação média do modelo, foi mais bem estimada empregando-se somente a área e densidade de drenagem. Observou-se que os índices atribuídos à variável precipitação nas equações ajustadas por Cortês (2004) são negativos, de maneira que maiores precipitações resultam menores vazões, o que contraria o fenômeno natural.

As equações ajustadas pelo Proni (Brasil, 1987), apesar de utilizarem somente a área como variável explicativa, apresentaram desempenho satisfatório na estimativa das vazões médias mensais da bacia, possivelmente devido à delimitação de regiões homogêneas hidrologicamente. $A Q_{7,10}$, no entanto, foi superestimada em relação ao observado e pode ser considerada inadequada.

A variável hidrológica de maior interesse na gestão dos recursos hídricos em Goiás é a Q95, empregada como vazão de referência para a gestão. Com exceção da equação 16, que teve desvio de mais de $144 \%$ em relação à vazão observada, as equações propostas por Cortês (2004) estimaram relativamente bem a $Q_{95}$. O melhor desempenho foi observado na equação 15, que utiliza área e densidade de drenagem como variáveis explicativas. Nessa situação específica, essa equação subestimou a vazão de referência, o que permite seu emprego na avaliação dos pleitos de outorga na bacia com maior segurança ao gestor.

Atualmente, por carência de postos de controle de vazões e de estudos de regionalização, que permitam o conhecimento da $\mathrm{Q}_{95} \mathrm{em}$ pequenas bacias agrícolas, onde estão concentrados os usos, o órgão gestor dos recursos hídricos em Goiás emprega medições pontuais no tempo e no espaço como referência às análises de pleitos de outorga. Como essas medições são pouco representativas do comportamento hidrológico das bacias, a porção que se permite captar é muito reduzida. Por esse motivo, mesmo as estimativas com certa margem de erro podem ser consideradas vantajosas em relação às vazões de referência atuais.

As equações $1,2,5,6,9,10,13$ e 14, que envolvem a precipitação média na bacia, puderam ser avaliadas pelos resultados estimados a cada ano com séries coincidentes de precipitação e vazão, considerando o coeficiente de correlação, o índice de concordância de Willmott $(d)$ e o índice $c$ (Tabela 4). Foram encontradas séries coincidentes de precipitação em todas as estações pluviométricas selecionadas e de vazão na estação fluviométrica 
FIOREZE, A. P.; OliveIRA, L. F. C.; FRANCO, A. P. B. Avaliação do desempenho de equações de regionalização de vazões na bacia hidrográfica do Ribeirão Santa Bárbara, Goiás, Brasil. Ambi-Agua, Taubaté, v. 3, n. 2, p. 62-76, 2008. (doi:10.4136/ambi-agua.53)

Fazenda Aliança de 1974 a 1978, 1980 a 1982, 1984 a 1990 e 1992 a 1996, totalizando 20 anos de dados.

Tabela 4. Avaliação das equações de regionalização de vazão propostas por Cortês (2004), na bacia hidrográfica do Ribeirão Santa Bárbara, Goiás, com coeficientes de correlação $(r)$, índice de concordância de Willmott (d), índice $c$ e desempenho.

\begin{tabular}{cccccc}
\hline Vazão & Equação & $\boldsymbol{r}$ & $\boldsymbol{d}$ & $\boldsymbol{C}$ & Desempenho \\
\hline \multirow{2}{*}{ Q $_{\text {MIN }}$} & 1 & 0,46 & 0,30 & 0,14 & Péssimo \\
& 2 & 0,46 & 0,34 & 0,15 & Péssimo \\
\hline \multirow{2}{*}{$\mathrm{Q}_{\text {MLP }}$} & 5 & 0,47 & 0,18 & 0,08 & Péssimo \\
& 6 & 0,47 & 0,22 & 0,11 & Péssimo \\
\hline \multirow{2}{*}{ Q $_{\text {MAX }}$} & 9 & 0,47 & 0,12 & 0,06 & Péssimo \\
& 10 & 0,47 & 0,15 & 0,07 & Péssimo \\
\hline \multirow{2}{*}{$Q_{95}$} & 13 & 0,49 & 0,34 & 0,17 & Péssimo \\
& 14 & 0,48 & 0,35 & 0,17 & Péssimo \\
\hline
\end{tabular}

Todos os coeficientes empregados indicaram péssimo desempenho das equações de regionalização de vazão propostas por Cortês (2004) que empregam a precipitação média como variável independente. As equações foram inadequadas para descrever as vazões de referência da bacia nos anos estudados, conforme exemplificado pelo ajuste obtido entre vazões observadas e simuladas pela equação 1 (Figura 5), e os resultados estimados por elas não devem ser empregados indiscriminadamente.

Equação 11

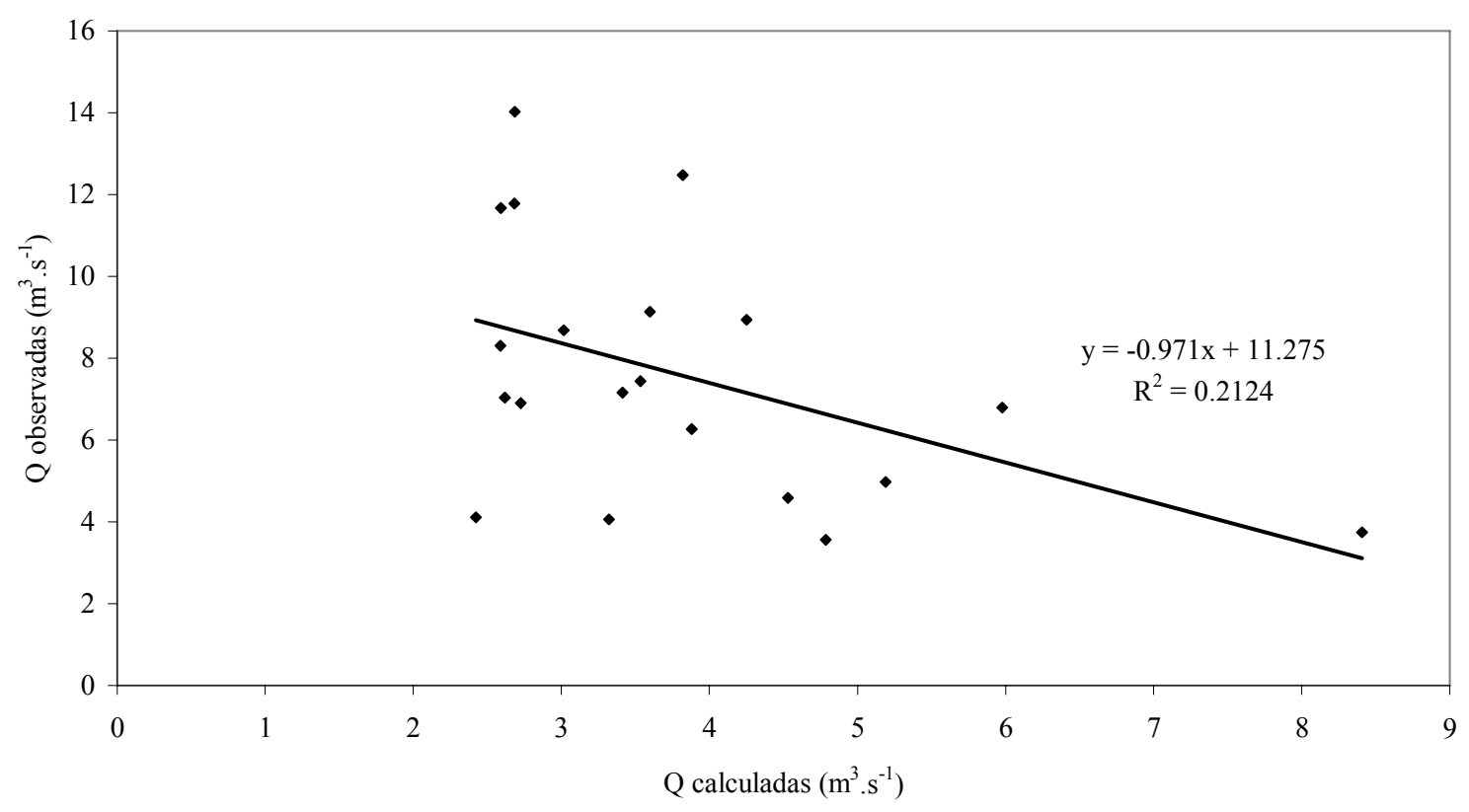

Figura 5. Vazões observadas na estação Fazenda Aliança, no Ribeirão Santa Bárbara, Goiás, e estimadas pelas equações propostas por Cortês (2004). 
FIOREZE, A. P.; OliveIRA, L. F. C.; FRANCO, A. P. B. Avaliação do desempenho de equações de regionalização de vazões na bacia hidrográfica do Ribeirão Santa Bárbara, Goiás, Brasil. Ambi-Agua, Taubaté, v. 3, n. 2, p. 62-76, 2008. (doi:10.4136/ambi-agua.53)

Na tentativa de obter uma calibração das equações geradas por Cortês (2004) que têm a precipitação média como variável independente, foram traçadas as curvas de correlação entre os valores observados nas séries de vazões e aqueles estimados pelas equações. Não foi alcançado um ajuste adequado para nenhuma das equações. Os coeficientes de determinação variaram de 21 a $24 \%$ e, devido a esses resultados, não foi possível determinar uma equação para calibração das equações.

\section{CONCLUSÃO}

Os modelos de regionalização avaliados apresentaram um bom desempenho na estimativa das vazões médias para a bacia hidrográfica do Ribeirão Santa Bárbara, mas inadequados para os eventos extremos (vazões máximas e mínimas). Aqueles gerados após a definição de regiões homogêneas têm desempenho notadamente melhor do que os que desconsideraram esse aspecto.

Os modelos de regionalização que têm a precipitação média na bacia hidrográfica como variável independente não permitiram a obtenção de uma equação para correção dos valores estimados, indicando que tais equações não são robustas a ponto de serem utilizadas indiscriminadamente.

O modelo que estima a $\mathrm{Q}_{95}$ permitiu sua estimativa com erro aceitável, produzindo resultados mais confiáveis que os fornecidos por poucas medições efetuadas no local de interesse, conforme praticado atualmente. A equação pode ser facilmente empregada em diferentes pontos da bacia e deve ser utilizada como apoio à gestão dos recursos hídricos.

\section{REFERÊNCIAS}

ALTERACH, J.; BARONTINI, S.; BAVERA, D.; CADORE, A.; DE LOTTO, P.; ZAINA, G. Regionalization procedures for the estimation of daily flow duration curves in the Italian Alps. Geophysical Research Abstracts, v. 8, 2006. Disponível em: $<$ http://www.geophysical-research-abstracts.net/>. Acesso em: 28 de julho de 2008.

ASSANI, A. A.; TARDIF, S.; BENSEGHIR, S.; CHALIFOUR, A.; MHAMED, M. Développement d'une nouvelle méthode de régionalisation basée sur le concept de « régime des débits naturels » : la méthod éco-géographique. Revue des Sciences de l'Eau, Québec, v. 19, n. 4, p. 365-380, 2006.

ARNÉZ, F. A. Análise de critérios de outorga do uso da água na bacia do rio Santa Maria, RS. 2002. Dissertação (Mestrado em Engenharia de Recursos Hídricos e Saneamento Ambiental) - Instituto de Pesquisas Hidráulicas, UFRGS, Porto Alegre, 2002.

BARBOSA, S. E. S.; BARBOSA JR., A. R.; SIlvA, G. Q.; CAMPOS, E. N. B.; RODRIGUES, V. C. Geração de modelos de regionalização de vazões máximas, médias de longo período e mínimas de sete dias para a bacia do Rio do Carmo, Minas Gerais. Revista Engenharia Sanitária e Ambiental, Rio de Janeiro, v. 10, n. 1, p. 64-71, 2005.

BRASIL. Ministério da Integração Social. Programa Nacional de Irrigação - PRONI. Disponibilidade Hídrica. Região do Rio dos Bois. Regionalização. Mapas. Brasília: Ministério da Irrigação, 1987. 
FIOREZE, A. P.; OLIVEIRA, L. F. C.; FRANCO, A. P. B. Avaliação do desempenho de equações de regionalização de vazões na bacia hidrográfica do Ribeirão Santa Bárbara, Goiás, Brasil. Ambi-Agua, Taubaté, v. 3, n. 2, p. 62-76, 2008. (doi:10.4136/ambi-agua.53)

CORTÊS, F. C. Obtenção e validação de modelos de regionalização de vazão na Bacia do Rio dos Bois, Estado de Goiás. 2004. Dissertação (Mestrado em Ciências Agrárias) Faculdade de Agronomia e Medicina Veterinária, UNB, Brasília, 2004.

CRUZ, J. C. Disponibilidade hídrica para outorga: avaliação de aspectos técnicos e conceituais. 2001. Tese (Doutorado em Engenharia) - Instituto de Pesquisas Hidráulicas, UFRGS, Porto Alegre, 2001.

EUCLYDES, H. P.; FERREIRA, P. A.; RUBERT, O. A. V.; SANTOS, R. M. Regionalização hidrológica na bacia do alto São Francisco a montante da barragem de Três Marias, Minas Gerais. Revista Brasileira de Recursos Hídricos, Porto Alegre, v. 6, n. 2, p. 81$105,2002$.

EUCLYDES, H. P. (coordenador). Atlas digital das águas de Minas: uma ferramenta para o planejamento e gestão dos recursos hídricos. Belo Horizonte: RURALMINAS/UFV, 2005.

FRANCO, A. P. B. Mapas de caracterização da bacia hidrográfica do Ribeirão Santa Bárbara, Goiás. Goiatuba, 2006. Escala 1:200.000. Disponível em: $<$ http://www.geonutri.com.br>. Acesso em: 11 de agosto de 2006.

LAAHA, G.; BLÖSCHL, G. A comparison of low flow regionalization methods - catchment grouping. Journal of Hydrology, v. 323, n. 1/4, p. 193 - 214, 2006.

MASSUEL, S.; CAPPELAERE, B. Hydrological model upscaling for regionalization os runoff flow and accumulation over the Amma-Niger meso-site. Geophysical Research Abstracts, v. 7, 2005. Disponível em: <http://www.geophysical-researchabstracts.net/>. Acesso em: 28 de julho de 2008.

MEDEIROS, A. T. Estimativa da evapotranspiração de referência a partir da equação de Penman-Monteith, de medidas lisimétricas e de equações empíricas, em Paraipaba, CE. 2002. Tese (Doutorado em Agronomia) - Escola Superior de Agricultura Luiz de Queiroz, USP, Piracicaba, 2002.

OBREGON, E.; TUCCI, C. E. M.; GOLDENFUM, J. A. Regionalização de vazões com base em séries estendidas: bacias afluentes à Lagoa Mirim, RS. Revista Brasileira de Recursos Hídricos, Porto Alegre, v. 4, n. 1, p. 57-75, 1999.

PARAJKA, J.; MERZ, R.; BLÖSCHL, G. A comparison of regionalisation methods for catchment model parameters. Hydrology and Earth System Sciences Discussions, v.2, p. 509-542, 2005.

RUSTEBERG, B. Recomendações referentes à criação de uma base de dados técnicos como subsídio para a outorga de direito de uso de recursos hídricos superficiais na bacia hidrográfica do Rio Meia Ponte - GO. Goiânia: Projeto Desenvolvimento Integrado e Sustentável do Rio Meia Ponte, 2003. Não publicado.

SILVA JR., O. B. Análise da escala das variáveis hidrológicas e do uso do solo na bacia do Potiribu - RS. 2001. Dissertação (Mestrado em Engenharia de Recursos Hídricos e Saneamento Ambiental) - Instituto de Pesquisas Hídricas, UFRGS, Porto Alegre, 2001.

SILVEIRA, G. L.; TUCCI, C. E. M. Monitoramento em pequenas bacias para a estimativa de disponibilidade hídrica. Revista Brasileira de Recursos Hídricos, Porto Alegre, v. 3, n. 3, p. 97-110, 1998. 
FIOREZE, A. P.; OliveIRA, L. F. C.; FRANCO, A. P. B. Avaliação do desempenho de equações de regionalização de vazões na bacia hidrográfica do Ribeirão Santa Bárbara, Goiás, Brasil. Ambi-Agua, Taubaté, v. 3, n. 2, p. 62-76, 2008. (doi:10.4136/ambi-agua.53)

SUGAI, M. R. V. B.; FILL, H. D.; GOMES, J. A. A importância do monitoramento na gestão de recursos hídricos. In: SIMPÓSIO INTERNACIONAL SOBRE GESTÃO DE RECURSOS HÍDRICOS, 1998, Gramado. Anais... Porto Alegre: Associação Brasileira de Recursos Hídricos, 1998.

TUCCI, C. E. M. Hidrologia - ciência e aplicação. 3. ed. Porto Alegre: UFRGS/ABRH, 2004.

UNIVERSIDADE FEDERAL DE VIÇOSA - UFV. Disponível em: $<$ http://www.ufv.br/dea/hidrotec $>$. Acesso em: 15 de outubro de 2004.

VIllela, S. M.; MATTOS, A. Hidrologia Aplicada. São Paulo: McGraw-Hill do Brasil, 1975. 